\title{
Effects of organically modified nanoclay on cellular morphology, tensile properties, and dimensional stability of flexible polyurethane foams
}

\author{
Reza Jahanmardi", Behrad Kangarlou and Arash Ranjbarzadeh Dibazar
}

\begin{abstract}
Flexible polyurethane/organically modified nanoclay (organoclay) nanocomposite foams were synthesized by a two-step reactive process. X-ray diffraction (XRD), scanning electron microscopy (SEM), and tensile and compression tests have been used in order to investigate clay dispersion, cellular morphology, tensile properties, and dimensional stability, respectively. The XRD patterns of a polyurethane foam sample containing $2 \mathrm{wt} . \%$ of nanoclay revealed clay intercalation. Furthermore, SEM images of the prepared foams showed that incorporation of clay into the polyurethane foams results in a reduction of cell size as well as an increase in cell density, and these phenomena were explained on the basis of nucleation promotion in the presence of clay. In addition, tensile modulus of the prepared foams was shown to be improved by incorporation of clay. The results obtained from the compression tests proved that the incorporation of clay into the polyurethane foams leads to deterioration of their dimensional stability. The results obtained from the mechanical studies were interpreted on the basis of physical and chemical interactions between clay surface and polyurethane chains.
\end{abstract}

Keywords: Nanocomposite foam; Cellular morphology; Compression set

\section{Background}

Flexible polyurethane foams are used in many applications because of their ease of handling, excellent cushioning, and tunable physical properties [1]. They are used in a variety of commercially established applications like mattresses, automotive and furniture cushions, and carpet backing, to name a few. The main reaction in polyurethane foam processing is the polycondensation of poly-hydroxy compounds (polyols) with diisocyanates. Foaming phenomenon occurs when a small amount of blowing agent and water is added during polymerization process. Water reacts with isocyanate groups giving carbamic acids, which spontaneously lose $\mathrm{CO}_{2}$, thus generating the foam bubbles [2]. Nevertheless, flexible polyurethane foams like other plastic foams have low mechanical strength and low dimensional stability that could inhibit their use in some important applications

\footnotetext{
* Correspondence: r.jahanmardi@srbiau.ac.ir

Department of Polymer Engineering, Science and Research Branch, Islamic Azad University, P. O. Box 14155-4933, Tehran 1477893855, Iran
}

such as shoe soles. The mechanical properties could be partly improved by modification of cellular morphology as microstructural studies on rigid polyurethane foams, which have indicated that the compressive strength and modulus of the foams increase by decreasing cell size and narrowing cell size distribution through changing blowing agent. On the other hand, in recent years, polymer nanocomposites have attracted much attention because of their high potential to achieve great improvement in properties including dimensional stability, gas permeability, flame retardancy, and mechanical properties by adding a small amount of nanoparticles in the polymer matrices [3-5]. Furthermore, it has been shown that incorporation of nanoparticles with their large surface area and fine dimensions as well as very close contact between particles and the polymer matrix could alter foam morphology and properties.

'Nanoclay' is the term generally used when referring to a clay mineral with a phyllosilicate or sheet structure with a thickness of the order of $1 \mathrm{~nm}$ and surfaces of 
perhaps 50 to $150 \mathrm{~nm}$ in one dimension [6]. The mineral base can either be natural or synthetic and is hydrophilic. The clay surfaces can be modified with specific methods to render them organophilic and therefore compatible with organic polymers. The main reasons for use of clays are accessibility, easy modification, cheapness, non-corrosiveness, and recyclability [7]. It has been proven that nanoclay, especially after exfoliation and surface modification, is an effective nucleation agent to enhance cell density and to increase the interaction with blowing agent. So, it seems that flexible polyurethane/ nanoclay nanocomposite foams represent more superior and practical properties compared with their counterpart conventional foams. Thus, a great deal of effort has been devoted to the development of polyurethane/nanoclay composites and foams in recent years $[4,8-10]$. It has been proved that the presence of clay results in an increase in cell density and a reduction of cell size compared to pure polyurethane foam. However, based on our best knowledge, there is no report describing the effect of incorporation of nanoclay on dimensional stability of flexible polyurethane foam. So, the present work was conducted in order to investigate the effects of incorporation of organically modified nanoclay on dimensional stability of flexible polyurethane foam. In this work, flexible polyurethane/organoclay foams were prepared using a two-step process. Then, the state of clay dispersion in prepared composite foams was studied using X-ray diffraction. Afterwards, the effect of clay incorporation on various characteristics of the prepared foams including cellular morphology, cell size, cell density, tensile properties, and dimensional stability was investigated.

\section{Results and discussion}

\section{Clay dispersion in the prepared nanocomposite foams}

The layered silicates of nanoclay can act as nucleation sites and increase cell density for final foam [11]. Interchangeably, it could be considered that layered silicates decrease energy barrier for cell nucleation. The reduction of the energy barrier in the presence of layered silicates is more pronounced than that of conventional fillers because nanoclay has larger surface area. Using nanoclay as nanofiller, two different morphologies may be obtained: intercalation and exfoliation. Intercalation occurs with penetration of polymer chains into the interlayer region of the clay with maintenance of the ordered structure. Exfoliation includes polymer chain penetration into nanoclay layers and crystallite delamination that causes random dispersion of individual nanometer-thick platelets of silicate in polymer matrix. Because of the larger surface area and larger aspect ratio of the nanoclay layers, the exfoliated structure generally provides the best improvement of tensile properties in resulted nanocomposite foam. In this work, nanoclay with a concentration of $2 \mathrm{wt} . \%$ was added to the polymer in order to study the morphology of the prepared polyurethane/ nanoclay composite using X-ray diffraction (XRD). The XRD patterns of the neat nanoclay (Cloisite ${ }^{\circ} 30 \mathrm{~B}$; BYK Additives $\mathrm{GmbH}$, Moosburg, Germany) and composite sample containing $2 \mathrm{wt} \%$ of nanoclay are shown in Figure 1. According to Equation 1 (see 'Methods' section), the space between nanoclay layers is equal to $18.5 \AA$ in pure nanoclay corresponding to the diffraction peak in the XRD pattern at $2 \theta=4.75$. Furthermore, as it is seen in Figure 1, XRD pattern of the composite sample has two weak diffraction peaks at $2 \theta=4.75^{\circ}$ and $2.2^{\circ}$, which could be assigned to the interlayer distances of 18.5 and $40.1 \AA$, respectively. So it could be concluded that the interlayer distance is increased profoundly for some clay stacks, but a portion of clay stacks remains intact. In addition, because of the low concentration of clay in the sample, it is not possible to judge, based on the weak diffraction peaks in the XRD pattern of the composite sample, whether exfoliation of some clay stacks occurred. Moreover, it should be noted that we used foam samples with lower concentrations of nanoclay in our study, but since the XRD pattern of these samples did not show any diffraction peak, we were obliged to prepare a composite sample containing $2 \mathrm{wt}$ \% of nanoclay. Furthermore, preparation of foam samples with concentrations above 2 wt.\% of nanoclay was impossible using our method.

\section{Cellular morphology of the prepared nanocomposite foams}

The effect of incorporation of nanoclay on cellular morphology of the prepared foam samples was studied. FESEM images of the neat polyurethane foam sample and the foam samples containing different concentrations of nanoclay are shown in Figure 2. By comparison of the images presented in Figure 2, it is seen that incorporation of clay into the polymer matrix leads to a finer and more uniform cellular morphology. Furthermore,

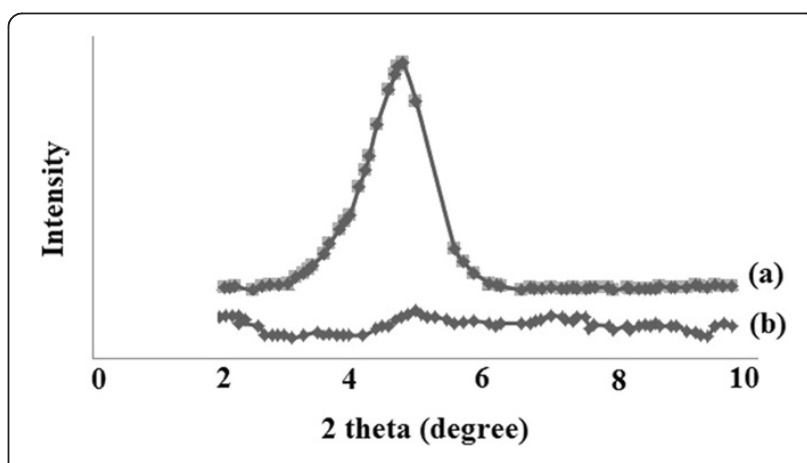

Figure 1 XRD pattern of (a) neat Cloisite ${ }^{\circledR} 30 \mathrm{~B}$ and (b) polyurethane/ organoclay foam sample containing $2 \mathrm{wt} . \%$ organoclay. 

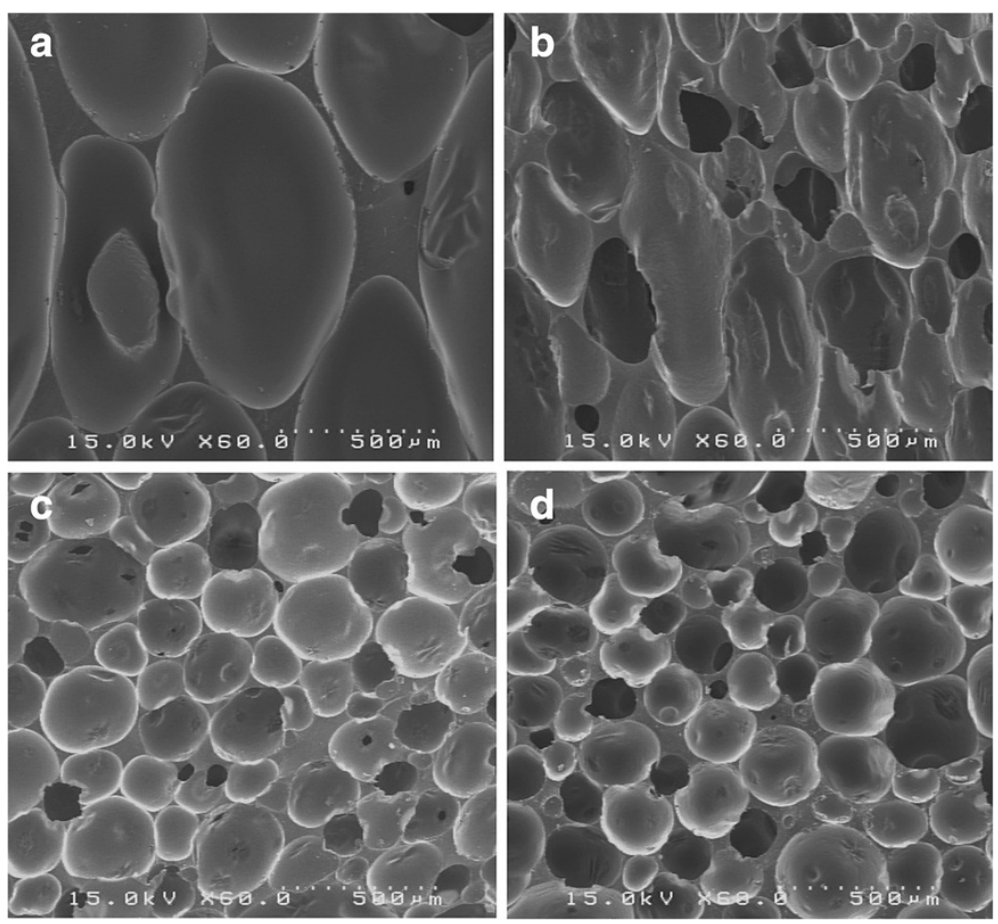

Figure 2 SEM images. Neat polyurethane foam sample (a). Polyurethane/organoclay foam samples containing (b) 0.25 wt.\%, (c) 0.50 wt.\%, and (d) 1 wt.\% of organoclay.

Table 1 shows the cell density of the samples calculated according to Equation 2 (see 'Methods'). As it is inferred from the data presented in Table 1, incorporation of clay into the polyurethane (PU) foam leads to a dramatic increase in cell density so that the cell density increases from 6 cells $\mathrm{mm}^{3}$ in the case of the neat polyurethane foam sample to 175 cells $\mathrm{mm}^{3}$ in the case of the foam containing $1 \mathrm{wt} . \%$ of the nanoclay. The obtained results could be explained by the classical nucleation theory which was suggested by Colton and Suh [12]. The theory predicts that as the energy-barrier for heterogeneous nucleation decreases due to the presence of filler particle, the nucleation rate increases and the nucleation time interval decreases and hence, almost instantaneous growth of cells is facilitated. Thus, finer and more uniform cellular morphology is obtained in the prepared polyurethane/clay foams because of the more and well-dispersed nucleation sites, which are due to the incorporation and uniform dispersion of clay.

Tensile properties of the prepared nanocomposite foams The results of tensile properties measurements of the samples are summarized in Table 2. As it could be deduced from the data presented in the table, incorporation of nanoclay with high intrinsic elastic modulus into the polyurethane foam increases tensile modulus. However, elongation at break of the polyurethane foam samples is decreased by incorporation of nanoclay. This phenomenon could be due to adsorption of the polymer chains on the surface of organoclay platelets which retards the extensibility of the polymer chains $[4,13,14]$.

\section{Dimensional stability of the prepared nanocomposite foams}

Compression set test was utilized to evaluate the dimensional stability of the prepared foam samples. It is believed that compression set of flexible polyurethane foams is sensitive to both network structure and cellular morphology [12]. Figure 3 shows the recovery curves of the foam samples obtained from compression tests at $70^{\circ} \mathrm{C}$. As it is seen, samples containing nanoclay show more compression set and hence, lower dimensional stability. However, the initial rate of dimensional recovery is similar for all the foam samples. This phenomenon could be attributed to the destruction and re-

\begin{tabular}{|c|c|c|}
\hline Sample designation & Organoclay (wt.\%) & $\begin{array}{l}\text { Cell density } \\
\text { (cells } / \mathrm{mm}^{3} \text { ) }\end{array}$ \\
\hline PU & 0.0 (neat polyurethane foam) & 6 \\
\hline PU/C25 & 0.25 & 56 \\
\hline PU/C50 & 0.50 & 133 \\
\hline PU/C100 & 1.00 & 172 \\
\hline
\end{tabular}

$\mathrm{PU}$, polyurethane. 
Table 2 Measured tensile properties of the prepared polyurethane/organoclay foam samples

\begin{tabular}{lll}
\hline $\begin{array}{l}\text { Sample } \\
\text { designation }\end{array}$ & $\begin{array}{l}\text { Tensile modulus } \\
(\mathrm{MPa})\end{array}$ & $\begin{array}{l}\text { Elongation at break } \\
\text { (\%) }\end{array}$ \\
\hline $\mathrm{PU}$ & $0.450 \pm 0.018$ & $426 \pm 17$ \\
$\mathrm{PU} / \mathrm{C} 25$ & $0.520 \pm 0.023$ & $419 \pm 21$ \\
$\mathrm{PU} / \mathrm{C50}$ & $0.535 \pm 0.021$ & $402 \pm 16$ \\
$\mathrm{PU} / \mathrm{C} 100$ & $0.562 \pm 0.025$ & $384 \pm 18$ \\
\hline
\end{tabular}

$\mathrm{PU}$, polyurethane.

establishment of physical bonds between clay surface and the polymer chains during the compression and relaxation stages, respectively, which favor compressed form and reduce the tendency to reach the initial form of the samples. In addition, nanoclay used in this study has $\mathrm{OH}$ groups on its surface and according to the hypothesis of Lee et al. might interact with -NCO groups of the diisocyanate $[3,15]$. Thus, the grafted clay may act as a shield which prevents the formation of hydrogen bonds between -NHCOO groups, as it is shown in Scheme 1.

Consequently, the grafted clay layers affect the formation of an elastic network structure of the polymer which, in turn, inhibits recovery of the chains after removing pressure, resulting in the deterioration of dimensional stability of the foam. It seems that the positive effects of nanoclay on cellular morphology of the foam samples which could improve dimensional stability cannot compete with the unfavorable effect of nanoclay on the network structure in this regard.

\section{Conclusions}

In this work, flexible polyurethane/organoclay nanocomposite foams containing various amounts of clay were prepared using a two-step procedure. X-ray diffraction patterns showed an intercalated structure for the sample containing highest concentration of nanoclay. It was also

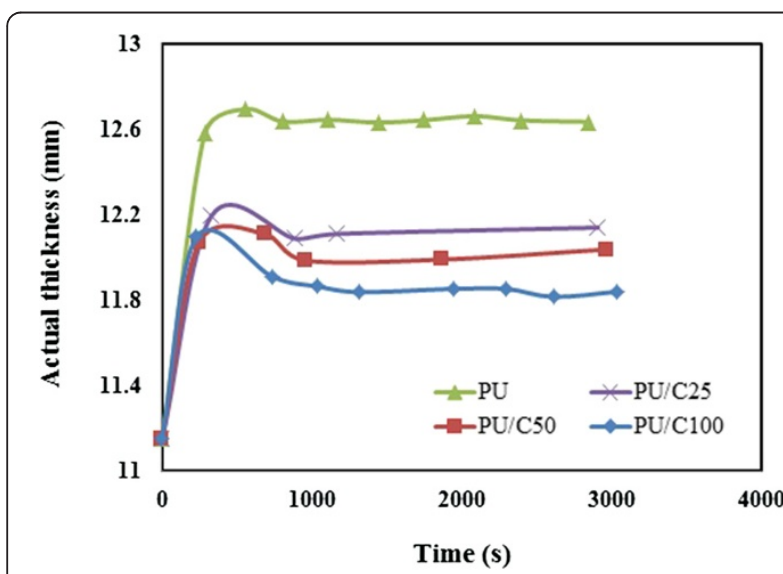

Figure 3 Recovery curves for the polyurethane foam samples obtained from compression tests at $70^{\circ} \mathrm{C}$. shown that the incorporation of nanoclay into the polyurethane foam samples leads to the increase in cell density and more uniform cellular morphology which were interpreted on the basis of classical nucleation theory by Colton and Suh. It was also shown that the incorporation of nanoclay into the polyurethane foam samples leads to an increase in tensile modulus as well as a decrease in elongation at break which was explained in terms of interactions between the polymer chains and surface of organoclay layers. Furthermore, the dimensional stability of the polyurethane foam samples was shown to be deteriorated by incorporation of nanoclay. In this regard, one can conclude that the chemical interaction of organoclay with polymer chains reduces the amount of junctions which are vital to form an elastic network in the polymer matrix.

\section{Methods}

\section{Materials}

In this study, organically modified nanonoclay (Cloisite 30B) from BYK Additives GmbH, Moosburg, Germany. was used. Amount of clay surface modification was equal to 90 meq per $100 \mathrm{~g}$ clay. Both polyurethane constituents, i.e., polyol mixture (including polyol, blowing agent, surfactant, and curing agent) and a high functionality methylene diphenyl diisocyanate (MDI), were obtained in liquid form from Coim Co. (Milan, Italy). The both polyurethane constituents were FX grade, a commercially used grade for production of shoe sole and were used as received.

\section{Synthesis of polyurethane nanocomposite foams}

In this work, the preparation of nanocomposite foam samples had two steps. In the first step, certain amount of dried nanoclay which was placed in an oven at $100^{\circ} \mathrm{C}$ for $6 \mathrm{~h}$ just before the experiment was mixed with certain amount of diisocyanate for about $5 \mathrm{~min}$ by high shear mixing at room temperature and 2,800 rpm in order to obtain exfoliated structure of clay nanolayers. In the second step, the mixture of diisocyanate and nanoclay was mixed with polyol mixture at the same conditions of the previous step. The amount of polyol mixture used was equal to that of diisocyanate for all the samples. The resulting mixture was then poured in a plastic mold immediately. The mold was then closed and immersed in a mixture of water and ice to avoid excess foam expansion which may lead to the final shrinkage. The prepared foams had $0.0 \%$ to $1.0 \%$ by weight of clay.

\section{Measurements and characterizations}

The d-spacing between nanoclay layers was measured by X-ray diffraction using a Philips model instrument equipped with cobalt radiation source of $40 \mathrm{kV}, 30 \mathrm{~mA}$, $\lambda=1.54 \mathrm{~nm}, 2 \theta=2^{\circ}$ to $10^{\circ}$, and imaging speed of $0.01 \mathrm{~s}^{-1}$. 


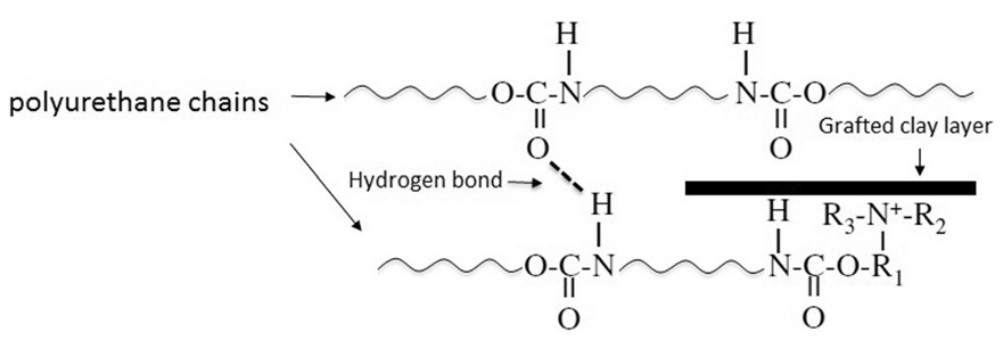

Scheme 1 The interference of grafted clay layer on hydrogen bonding in polyurethane [3].

The peak position in the spectrum and the Bragg equation as can be seen in Equation 1 were used to calculate distances between clay layers:

$$
n \lambda=2 d \sin \theta
$$

Since we were not able to have any interpretation based on the XRD patterns of the samples containing less than $1 \%$ by weight of clay due to lack of any diffraction peaks, a composite sample containing 2 wt.\% of clay was prepared using the same procedure for the preparation of the other samples and used only for the sake of $\mathrm{X}$-ray diffraction.

The morphology of the prepared nanocomposite foams was observed by field emission scanning electron microscopy (FESEM) using a Leo 440i unit. Specimens for FESEM were $1 \times 1 \times 1 \mathrm{~cm}^{3}$ cut with sharp blade from the nanocomposite foam samples. The cut specimens were held in argon plasma and coated with gold for 3 min. Images were obtained using $15 \mathrm{kV}$ accelerating voltage. Cell density (number of cells per cubic centimeter) of the prepared foams $\left(N_{\mathrm{f}}\right)$ was obtained using Equation 2, in which $A$ is the area in SEM image on the order of square centimeter, $M$ is the magnification factor and $n$ is the number of cells in the SEM image [11]:

$$
N_{\mathrm{f}}=\left(\frac{n M^{2}}{A}\right)^{\frac{3}{2}}
$$

Tensile tests were performed on dumbbell-shaped specimens according to ASTM D 412 using a Testometric testing machine (Testometric Co., Rochdale, Lancashire, UK) with a load cell of $5 \mathrm{kN}$ and selftightening roller grips. The specimens were stamped out from nanocomposite foam samples. The narrow section of the dumbbell-shaped specimens had dimensions of $20 \times 4 \times 2 \mathrm{~mm}^{3}$, respectively. Test specimens were prepared from foam panels in the flow direction (thickness was in the foam rise direction). In order to remove skins from the specimens' surfaces we used chipper. Five specimens per sample were tested. The tests were run at a speed of $500 \mathrm{~mm} \mathrm{~min}^{-1}$.
The constant deflection compression set was measured according to ASTM D 3574 (test D). Specimens were $50 \times 50 \times 22.5 \mathrm{~mm}^{3}$ and deflected to $50 \%$ of their original thickness. Then, they were placed in a forced air circulating oven at $70^{\circ} \mathrm{C}$ for $22 \mathrm{~h}$. Compression device consisting of two flat plates was arranged so that the plates were held parallel to each other; the plates were adjustable to the required deflection thickness. Three specimens per sample were tested. The actual thickness of the samples was measured and recorded as a function of time. Afterwards, the samples were brought out from the compression device. As the test for the different samples were performed at different times, time intervals at which measurements were carried out were not essentially similar for all the samples.

\section{Competing interests}

The authors declare that they have no competing interests.

\section{Authors' contributions}

RJ proposed the study, performed the statistical analysis, revised, drafted manuscript, and financially supported the project. BK carried out the experiments and drafted the manuscript, and ARD carried out the experiments and helped to perform the statistical analysis and to draft the manuscript. All authors read and approved the final manuscript.

Received: 9 September 2013 Accepted: 30 October 2013 Published: 12 Nov 2013

\section{References}

1. Lefebvre, J, Bastin, B, Le Bras, M, Duquesne, S, Paleja, R, Delobel, R: Thermal stability and fire properties of conventional flexible polyurethane foam formulations. Polym. Degrad. Stab. 88, 28-34 (2005)

2. Esmaeilnezhad, E, Rezaei, M, Razavi, MK: The effect of alternative blowing agents on microstructure and mechanical characteristics of rigid polyurethane foam. Iran. Polym. J. 18, 569-579 (2009)

3. Lee, LJ, Zeng, C, Cao, X, Han, X, Shen, J, Xu, G: Polymer nanocomposite foams. Compos. Sci. Technol. 65, 2344-2363 (2005)

4. Cao, X, Lee, L, Widya, T, Macosko, C: Polyurethane/clay nanocomposites foams: processing, structure and properties. Polymer 46, 775-783 (2005)

5. Alexandre, M, Dubois, P: Polymer-layered silicate nanocomposites: preparation, properties and uses of a new class of materials. Mater. Sci. Eng. R. Rep. R28, 1-63 (2000)

6. Sedaghat, S: Synthesis of clay-CNTs nanocomposite. J. Nanostruct. Chem. 3, 24 (2013)

7. Shirini, F, Mamaghani, M, Atghia, SV: Sulfonic acid functionalized ordered nanoporous $\mathrm{Na}+$ montmorillonite as an efficient and recyclable catalyst for the chemoselective methoxymethylation of alcohols. J. Nanostruct. Chem. 3, 2 (2012) 
8. Madaleno, L, Pyrz, R, Crosky, A, Jensen, LR, Rauhe, JCM, Dolomanova, V, Timmons, AMMVB, Pinto, JJC, Norman, J: Processing and characterization of polyurethane nanocomposite foam reinforced with montmorillonite-carbon nanotube hybrids. Compos. Part A-Appl. Sci. 44, 1-7 (2013)

9. Tien, YI, Wei, KH: High-tensile-property layered silicates/polyurethane nanocomposites by using reactive silicates as pseudo chain extenders. Macromolecules 34, 9045-9052 (2001)

10. Han, X, Zeng, C, Lee, L, Koelling, KW, Tomasko, DL: Extrusion of polystyrene nanocomposite foams with supercritical $\mathrm{CO}_{2}$. Polym. Eng. Sci. 43, 1261-1275 (2003)

11. Wee, D, Seong, DG, Youn, JR: Processing of microcellular nanocomposite foams by using a supercritical fluid. Fiber. Polym. 2, 160-169 (2004)

12. Dounis, DV, Wilkes, GL: Structure-property relationships of flexible polyurethane foams. Polymer 38, 2819-2828 (1997)

13. Kabir, ME, Saha, MC, Jeelani, S: Effect of ultrasound sonication in carbon nanofibers/polyurethane foam composites. Mater. Sci. Eng. A 459, 111-116 (2007)

14. Mohamad, N, Muchtar, A, Ghazali, MJ, Dahlan, HM, Azhari, CH: Epoxidised natural rubber-alumina nanoparticle composites (ENRAN): effect of filler loading on the tensile properties. J. Solid. State. Sci. Tech. 17, 133-143 (2009)

15. Semenzato, S, Lorenzetti, A, Modesti, M, Ugel, E, Hrelja, D, Besco, S, Michelin, RA, Sassi, A, Facchin, G, Zorzi, F, Bertan, R: A novel phosphorus polyurethane foam/montmorillonite nanocomposite: preparation, characterization and thermal behavior. Appl. Clay Sci. 44, 35-42 (2009)

10.1186/2193-8865-3-82

Cite this article as: Jahanmardi et al:: Effects of organically modified nanoclay on cellular morphology, tensile properties, and dimensional stability of flexible polyurethane foams. Journal Of Nanostructure in Chemistry 2013, 3:82

\section{Submit your manuscript to a SpringerOpen ${ }^{\circ}$ journal and benefit from:}

- Convenient online submission

- Rigorous peer review

- Immediate publication on acceptance

- Open access: articles freely available online

- High visibility within the field

- Retaining the copyright to your article

Submit your next manuscript at $\boldsymbol{\wedge}$ springeropen.com 